\title{
Degradation of pentachlorophenol by Phanerochaete chrysosporium: intermediates and reactions involved
}

\author{
G. Vijay Bhasker Reddy and Michael H. Gold
}

Department of Biochemistry and Molecular Biology, Oregon Graduate Institute of Science and Technology, 20000 NW Walker Road, Beaverton, OR 97006-8921, USA
Author for correspondence: Michael H. Gold. Tel: +1 503748 1076. Fax: +1 5037481464. e-mail:mgold@bmb.ogi.edu

Under nitrogen-limiting, secondary metabolic conditions, the lignin-degrading basidiomycete Phanerochaete chrysosporium rapidly degrades pentachlorophenol. The pathway for the degradation of pentachlorophenol has been elucidated by the characterization of fungal metabolites and oxidation products generated by purified lignin peroxidase (LiP) and manganese peroxidase (MnP). The multi-step pathway is initiated by a LiP- or MnP-catalysed oxidative dechlorination reaction to produce tetrachloro-1,4benzoquinone. Under primary or secondary metabolic conditions, the quinone is further degraded by two parallel pathways with cross-links. The quinone is reduced to tetrachlorodihydroxybenzene, which can undergo four successive reductive dechlorinations to produce 1,4-hydroquinone, and the latter is 0 hydroxylated to form the final aromatic metabolite, 1,2,4-trihydroxybenzene. Alternatively, the tetrachloro-1,4-benzoquinone is converted, either enzymically or nonenzymically, to 2,3,5-trichlorotrihydroxybenzene, which undergoes successive reductive dechlorinations to produce 1,2,4-

trihydroxybenzene. Finally, at several points, hydroxylation reactions convert chlorinated dihydroxybenzenes to chlorinated trihydroxybenzenes, linking the two pathways at each of these steps. Presumably, the 1,2,4-trihydroxybenzene produced in each pathway is ring-cleaved with subsequent degradation to $\mathrm{CO}_{2}$. In contrast to the oxidative dechlorination step, the reductive dechlorinations and hydroxylations occur during both primary and secondary metabolic growth. Apparently, all five chlorine atoms are removed from the substrate prior to ring cleavage.

Keywords: pentachlorophenol, reductive dechlorination, hydroxylation, Phanerochaete chrysosporium, lignin and manganese peroxidases

\section{INTRODUCTION}

Pentachlorophenol (PCP or Penta) was first produced in the 1930s as a wood preservative and it has subsequently been used as a biocide against a wide variety of species (Crosby, 1981). The large-scale use of PCP has led to the contamination of terrestrial and aquatic ecosystems. Owing to its toxicity, PCP is on the list of priority pollutants defined by the US Environmental Protection Agency (Keither \& Teilard, 1979; Moos et al., 1983).

The degradation of PCP by soil bacteria (Chu \& Kirsch,

Abbreviations: $\mathrm{HC} / \mathrm{HN}$, high carbon/high nitrogen; $\mathrm{HC} / \mathrm{LN}$, high carbon/low nitrogen; LiP, lignin peroxidase; MnP, manganese peroxidase; PCP, pentachlorophenol.
1972; Saber \& Crawford, 1985 ; Apajalahti \& SalkinojaSalonen, 1987; Schenk et al., 1989; Radehaus \& Schmidt, 1992), particularly by Mycobacterium chlorophenolicum (formerly Rhodococcus chlorophenolicus) (Apajalahti \& Salkinoja-Salonen, 1987; Häggblom et al., 1989, 1994) and Sphingomonas chlorophenolica (formerly Flavobacterium sp.) (Steiert \& Crawford, 1986) has been examined extensively. In both bacterial systems, PCP is first oxidized to tetrachlorohydroquinone by a PCP monooxygenase (Häggblom et al., 1989; Xun \& Orser, 1991; Xun et al., 1992). In $M$. chlorophenolicum, the reaction sequence for the dechlorination of tetrachlorohydroquinone involves an initial oxidative dechlorination to form trichlorotrihydroxybenzene, which undergoes successive reductive dechlorinations to yield 1,2,4-trihydroxybenzene 
(Apajalahti \& Salkinoja-Salonen, 1987). In contrast, in S. chlorophenolica, tetrachloro-1,4-dihydroxybenzene undergoes two successive reductive dechlorinations (Steiert \& Crawford, 1986; Xun \& Orser, 1992; Copley, 1998).

Phanerochaete chrysosporium, a lignin-degrading white-rot fungus, is known to mineralize several chlorinated phenols, including PCP (Bumpus \& Aust, 1987; Hammel \& Tardone, 1988; Mileski et al., 1988; Valli \& Gold, 1991; Joshi \& Gold, 1993; Armenante et al., 1994; Reddy et al., 1998); however, to date, the pathway(s) for PCP degradation has not been adequately elucidated in this organism. Under nutrient nitrogenlimiting conditions, P. chrysosporium produces two extracellular haem peroxidases - lignin peroxidase (LiP) and manganese peroxidase $(\mathrm{MnP})$ - which, along with an $\mathrm{H}_{2} \mathrm{O}_{2}$-generating system, are involved in the oxidation of lignin and lignin model compounds (Buswell \& Odier, 1987; Kirk \& Farrell, 1987; Gold et al., 1989; Higuchi, 1990). LiP can oxidize PCP to tetrachlorobenzoquinone (Hammel \& Tardone, 1988; Mileski et al., 1988). In addition, in soil cultures of P. chrysosporium, the O-methylation of PCP has been reported (Lamar et al., 1990). Apart from the identification of these metabolites, the pathway for the degradation of PCP in P. chrysosporium has not been established.

Recently, we discovered that reductive dechlorination reactions are involved in the degradation of 2,4,6trichlorophenol by $P$. chrysosporium and several other white-rot fungi (Reddy et al., 1998), and we described a two-component reductive dechlorination enzyme system which is involved in the reductive dechlorination of chlorinated phenols (Reddy \& Gold, 1999). This prompted us to examine the degradation pathway for PCP in this organism. We here confirm that the initial dechlorination at the 4-position is catalysed by LiP or $\mathrm{MnP}$ as described previously for LiP (Hammel \& Tardone, 1988; Mileski et al., 1988); however, we now show that the remaining chlorines are removed by reductive dechlorination.

\section{METHODS}

Chemicals. Roman numerals in the text correspond to the Roman numerals presented in Figs 2, 3 and 4. PCP (I) was obtained from Aldrich; tetrachlorobenzoquinone (II) and 2chlorohydroquinone (XIV) were obtained from Pfaltz \& Bauer; 2,6- and 2,5-dichlorobenzoquinone were obtained from Sigma; 1,2,4-trihydroxybenzene (XVIII) was obtained from Lancaster Synthesis. Chemicals obtained commercially were purified by recrystallization prior to use.

Synthesis of intermediates. Tetrachloro-1,4-dihydroxybenzene (III) was prepared from tetrachlorobenzoquinone (II) by reduction with sodium dithionite. 1,4-Dimethoxytetrachlorobenzene (IX) and tetrachloro-4-methoxyphenol (X) were prepared from tetrachlorohydroquinone (III) by treatment with diazomethane in ether (Furniss et al., 1989). Dichlorotrihydroxybenzene (VII) was prepared from trihydroxybenzene (XVIII) as described previously (Friedman \& Ginsburg, 1958). Trihydroxybenzene $(1 \mathrm{mmol})$ was refluxed with $\mathrm{N}$-chlorosuccinimide $(3 \mathrm{mmol})$ and benzoyl peroxide
$(1 \mathrm{mg})$ in ether $(10 \mathrm{ml})$ for $12 \mathrm{~h}$. The reaction mixture was cooled and filtered to remove most of the $\mathrm{N}$-chlorosuccinimide (Friedman \& Ginsburg, 1958). The organic phase was washed with water, dried over anhydrous sodium sulphate and evaporated under reduced pressure to yield the crude product, which was purified by preparative TLC (hexane/ethyl acetate, $1: 1)$. Trichlorodihydroxybenzene $(\mathrm{V})$ was prepared from 2,6dichloro-1,4-dihydroxybenzene $(1 \mathrm{mmol})$ by refluxing with $\mathrm{N}$-chlorosuccinimide (1 mmol) as described above. The product $(\mathrm{V})$ was purified by HPLC.

Culture conditions. $P$. chrysosporium strain OGC101 (Alic et al., 1987) was grown from a conidial inoculum at $37^{\circ} \mathrm{C}$ in stationary cultures in $250 \mathrm{ml}$ flasks as described previously (Gold et al., 1982). The medium (25 ml) was as described previously (Kirk et al., 1978; Gold et al., 1982) and contained $2 \%$ glucose [high carbon (HC)], $20 \mathrm{mM}$ sodium 2,2-dimethyl succinate $(\mathrm{pH} 4.5)$ as the buffer, and either $1.2 \mathrm{mM}$ [low nitrogen $(\mathrm{HC} / \mathrm{LN})$ ] or $12 \mathrm{mM}$ [high nitrogen $(\mathrm{HC} / \mathrm{HN})$ ] ammonium tartrate as the nitrogen source. Cultures were incubated under air for $3 \mathrm{~d}$, after which they were purged with $99 \cdot 9 \% \mathrm{O}_{2}$ at $3 \mathrm{~d}$ intervals.

Metabolism of PCP and metabolic intermediates. After $6 \mathrm{~d}$ incubation ( $3 \mathrm{~d}$ for $\mathrm{HC} / \mathrm{HN}$ cultures), the substrates, in $30 \mu \mathrm{l}$ ethanol, were added to cultures to a final concentration of $250 \mu \mathrm{M}$. After the indicated periods, products were reduced, extracted, acetylated and analysed by GC-MS and GC as described previously (Reddy et al., 1998). Quinones were analysed directly by HPLC without prior reduction as described previously (Reddy et al., 1998; Reddy \& Gold, 1999).

Enzymes. LiP and MnP were purified from the extracellular medium of acetate-buffered, agitated cultures of $P$. chrysosporium strain OGC101 as described previously (Gold et al., 1984; Glenn \& Gold, 1985; Wariishi \& Gold, 1990). The LiP (Gold et al., 1984) and MnP (Glenn \& Gold, 1985) concentrations were determined as described previously.

Enzyme reactions. LiP and $\mathrm{MnP}$ reactions were performed as described previously (Joshi \& Gold, 1993; Reddy et al., 1998). Veratryl alcohol $(0 \cdot 1 \mathrm{mM})$ was added to stimulate LiP reactions (Kirk \& Farrell, 1987; Wariishi \& Gold, 1990; Joshi \& Gold, 1994). Reaction mixtures were extracted with ethyl acetate, evaporated under $\mathrm{N}_{2}$ and analysed by GC or GC-MS after acetylation as described previously (Joshi \& Gold, 1993). For reductive acetylation, sodium dithionite was added to the reaction mixture before extraction. Quinone products were analysed by HPLC without prior reduction. Reaction mixtures were filtered through a Centricon 10 (Amicon) filter prior to direct HPLC analysis. Control reactions were conducted in the absence of either enzyme or $\mathrm{H}_{2} \mathrm{O}_{2}$ as described previously (Reddy et al., 1998).

Tetrachlorobenzoquinone (II) reduction. Six-day-old $P$. chrysosporium stationary cultures, grown under HC/LN conditions, were filtered through a Buchner funnel to separate the cells and extracellular medium. The hyphae were washed and resuspended in buffer or in fresh culture medium. Tetrachlorobenzoquinone (II) $(0 \cdot 1 \mathrm{mM})$ was added to the cell suspension or to the extracellular medium as described previously (Joshi \& Gold, 1993; Reddy et al., 1998) and incubated at $30{ }^{\circ} \mathrm{C}$ for $30 \mathrm{~min}$. At the end of the incubation period, the reaction mixtures were acidified, extracted and evaporated as described above and previously (Reddy et al., 1998).

Chromatography and spectrometry. GC-MS was performed at $70 \mathrm{eV}$ on a VG Analytical $7070 \mathrm{E}$ mass spectrometer as 
described previously (Joshi \& Gold, 1993; Reddy et al., 1998). Product quantitation was carried out on an HP 5890 II gas chromatograph. HPLC product analysis was conducted as described previously (Reddy et al., 1998). Products were detected at $285 \mathrm{~nm}$, and product yields on HPLC were quantified using calibration curves obtained with standards.

\section{RESULTS}

Time courses for the removal of PCP (I) and the key intermediate tetrachlorodihydroxybenzene III (Reddy \& Gold, 1999) from cultures of P. chrysosporium are shown in Fig. 1. After a $30 \mathrm{~h}$ incubation period, only $\sim 10 \%$ of the PCP remained in nitrogen-limited $(1.2 \mathrm{mM}$ ammonium tartrate) $\mathrm{HC} / \mathrm{LN}$ cultures, while $\sim 90 \%$ of the substrate remained under nutrientsufficient (12 mM ammonium tartrate) HC/HN conditions. In contrast, tetrachlorodihydroxybenzene (III), an initial intermediate in PCP degradation, was degraded more rapidly under nitrogen-sufficient conditions than under nitrogen-limited conditions.

\section{Metabolism of PCP and metabolic intermediates}

Products and yields obtained from the fungal metabolism of PCP (I) and of several intermediates are shown in Fig. 2. Under HC/LN conditions, three products tetrachlorodihydroxybenzene (III), tetrachlorobenzoquinone (II) and, in trace amounts, pentachloroanisole (IV) - were identified as metabolites of PCP (Fig. 2a).

When tetrachlorodihydroxybenzene (III) was added to cultures, the following metabolites were identified:

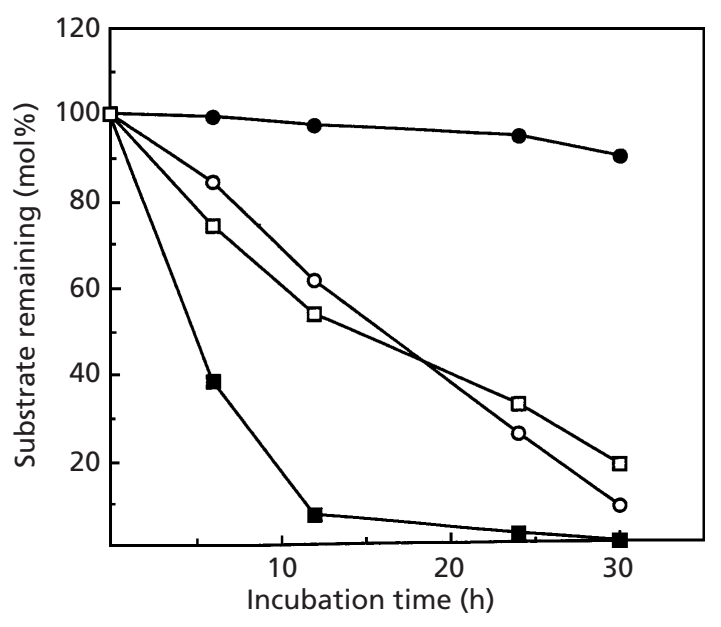

Fig. 1. The effect of nutrient nitrogen concentration on the degradation of PCP and tetrachlorodihydroxybenzene. Six-dayold cultures of $P$. chrysosporium, containing $1.2(\bigcirc, \square)$ or 12 $(\bullet, \square) \mathrm{mM}$ ammonium tartrate, were inoculated with PCP $(\bigcirc$, -) or tetrachlorodihydroxybenzene $(\square, \square)$ as described in the text. Cultures were incubated, purged with $\mathrm{O}_{2}$ periodically and extracted as described in the text. The substrate remaining was determined by HPLC as described in the text. The values presented are the means of triplicate experiments. Individual points fell within $\pm 5 \%$ of the mean. 2,3,5-trichloro-1,4-dihydroxybenzene (V), trichloro1,2,4-trihydroxybenzene (VI), dichlorotrihydroxybenzene (VII), tetrachloro-4-methoxyphenol (X), tetrachloro-1,4-dimethoxybenzene (IX) and a trace amount of tetrachlorobenzoquinone (II) (Fig. 2b). The metabolite trichlorotrihydroxybenzene (VI) was also formed when tetrachlorobenzoquinone (II) or tetrachlorohydroquinone (III) was incubated in water (data not shown).

When the metabolite trichlorodihydroxybenzene (V) was added to P. chrysosporium cultures (Fig. 2c), three major aromatic products were identified: 2,5-dichloro1,4-dihydroxybenzene (XI), 3,5,6-trichloro-1,2,4-trihydroxybenzene (VI) and dichlorotrihydroxybenzene (VII). The methylated metabolites 2,3,5-trichloro-4methoxyphenol (XII) and 2,3,5-trichloro-1,4-dimethoxybenzene (XIII) were also detected in trace amounts. When dichlorotrihydroxybenzene (VII) (Fig. 2d) was added to cultures, only 5-chloro-1,2,4-trihydroxybenzene (VIII) could be identified as a metabolite.

Finally, when 2,5-dichloro-1,4-dihydroxybenzene (XI) was added to cultures (Fig. 2e), the following metabolites were identified: 2-chloro-1,4-dihydroxybenzene (XIV), 5-chloro-1,2,4-trihydroxybenzene (VIII), 1,2,4trihydroxybenzene (XVIII), 2,5-dichloro-1,3,4-trihydroxybenzene (XVII), 2,5-dichloro-1,4-dimethoxybenzene (XV) and 2,5-dichloro-4-methoxyphenol (XVI). The metabolite 2,5-dichloro-1,3,4-trihydroxybenzene (XVII) was also formed in small quantities when 2,5-dichloro-1,4-dihydroxybenzene (XI) was incubated in water.

Under HC/HN conditions, PCP (I) slowly underwent Omethylation to form pentachloroanisole (IV) as the sole product ( $1 \%$ after $3 \mathrm{~d}$ incubation). However, under these $\mathrm{HC} / \mathrm{HN}$ conditions, the transformations of the PCP metabolites tetrachlorodihydroxybenzene (III), trichlorodihydroxybenzene (V), dichlorotrihydroxybenzene (VII) and 2,5-dichlorodihydroxybenzene (XI) were similar to those observed under $\mathrm{HC} / \mathrm{LN}$ conditions (Fig. 2).

The metabolites were identified by comparing their retention times on GC and their mass spectra with standards (Table 1). The HPLC retention times (in min) for metabolites were as follows: tetrachloro-1,4dihydroxybenzene (III), 10.3; tetrachloro-1,4-benzoquinone (II), 11.7; trichloro-1,4-dihydroxybenzene (V), 9.5; 2,6-dichlorotrihydroxybenzene (VII), 6.35; 5chloro-1,2,4-trihydroxybenzene (VIII), $6 \cdot 2$; tetrachloro1,4-dimethoxybenzene (IX), 5·3; 2,5-dichloro-1,4-dihydroxybenzene (XI), 8.5; 2,5-dichloro-1,4-dimethoxybenzene (XV), 12.4; 1,2,4-trihydroxybenzene (XVIII), $3 \cdot 4$.

\section{Enzymic oxidation of PCP and tetrachlorodihydroxybenzene}

The MnP- and LiP-catalysed oxidations of PCP and tetrachlorodihydroxybenzene (III) are shown in Fig. 3. Both peroxidases oxidized PCP (I) to yield tetra- 
(a)

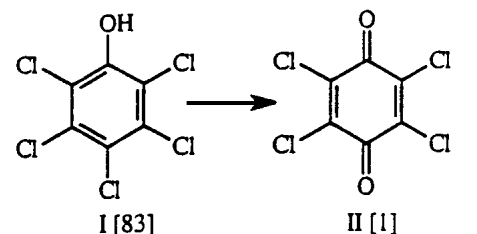<smiles>Oc1c(Cl)c(Cl)c(Cl)c(Cl)c1Cl</smiles><smiles>COc1c(Cl)c(Cl)c(Cl)c(Cl)c1Cl</smiles>

(b)<smiles>CC(Cl)(Cl)Cc1c(O)cc(Cl)c(O)c1Cl</smiles><smiles>O=C1C(Cl)=C(Cl)C(=O)C(Cl)=C1Cl</smiles><smiles>Oc1cc(O)c(Cl)cc1O</smiles>

(c)<smiles>Oc1c(O)c(Cl)c(Cl)c(O)c1Cl</smiles><smiles>[R19]Oc1c(Cl)c(Cl)c(OC)c(Cl)c1Cl</smiles><smiles>[X]Oc1c(Cl)c(Cl)c(O)c(Cl)c1Cl</smiles><smiles>CC[AsH3]</smiles><smiles>COc1c(Cl)cc(O)c(Cl)c1Cl</smiles><smiles>COc1cc(Cl)c(O[W])c(Cl)c1Cl</smiles>

(d)<smiles>Oc1ccc(O)c(O)c1</smiles><smiles>Oc1c(O)c(Cl)c(Cl)c(O)c1Cl</smiles>

XIII [t]

(e)<smiles>Oc1cc(O)c(O)c(O)c1</smiles>

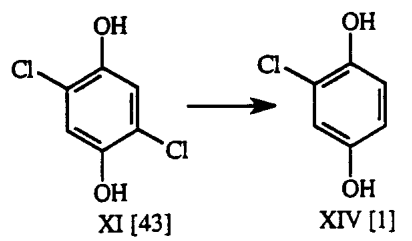<smiles>Oc1cc(O)c(Cl)cc1O</smiles><smiles>COc1cc(Cl)c(OC)cc1Cl</smiles><smiles>COc1cc(Cl)c(O)cc1Cl</smiles><smiles>Oc1ccc(O)c(O)c1</smiles>

Fig. 2. Metabolites identified from the degradation of $P C P$ and pathway intermediates by $P$. chrysosporium. Cultures were incubated, extracted and products analysed as described in the text. HPLC was used to determine the yields of quinones. GC was used to determine the yields of other compounds. Amounts of substrate remaining (\%) or percentage yields of products, following incubations of $6 \mathrm{~h}$, are given in square brackets; $t$, trace. Roman numerals identifying compounds in the figure correspond to those in the text. 
Table 1. Mass spectra of products, or derivatives, from the metabolism of PCP and intermediates by $P$. chrysosporium cultures and enzyme oxidations

Culture conditions, extractions, product analysis and reaction conditions were as described in Methods. Products from the oxidation of substrates by purified MnP and LiP were identified as described in the text. Reaction conditions and analysis were as described in the text. Retention times and mass spectra of standard compounds were essentially identical to those of the substrates and identified metabolites.

\begin{tabular}{|c|c|c|}
\hline Derivatized substrate or metabolite* & $\begin{array}{l}\text { GC retention } \\
\text { time }(\min )\end{array}$ & Mass spectrum $m / z$ (relative intensity) \\
\hline Pentachloroacetoxybenzene & $12 \cdot 48$ & $\begin{array}{l}312(3 \cdot 0), 310(10 \cdot 0), 308(16 \cdot 5), 306(10 \cdot 3), 272(3 \cdot 1) \\
270(20 \cdot 3), 268(64 \cdot 1), 266(100), 264(59 \cdot 5), 241(2 \cdot 8), \\
239(8 \cdot 8), 237(14 \cdot 5), 235(8 \cdot 3)\end{array}$ \\
\hline Tetrachloro-1,4-diacetoxybenzene & $13 \cdot 59$ & $\begin{array}{l}334(3 \cdot 8), 332(6 \cdot 3), 330(4 \cdot 8), 292(6 \cdot 3), 290(10 \cdot 8), 288 \\
\quad(9 \cdot 3), 252(11 \cdot 5), 250(49 \cdot 1), 248(100), 246(78 \cdot 1)\end{array}$ \\
\hline Trichloro-1,2,4-triacetoxybenzene & $14 \cdot 83$ & $\begin{array}{l}316(5 \cdot 2), 314(13 \cdot 1), 312(11 \cdot 1), 274(10 \cdot 0), 272(37 \cdot 1) \\
270(40 \cdot 7), 232(33 \cdot 2), 230(95 \cdot 3), 228(100)\end{array}$ \\
\hline $\begin{array}{l}\text { 2,3,5,6-Tetrachloro-1-acetoxy-4- } \\
\text { methoxybenzene }\end{array}$ & $12 \cdot 56$ & $\begin{array}{l}308(0 \cdot 5), 306(3 \cdot 5), 304(5 \cdot 0), 302(4 \cdot 1), 266(11 \cdot 6), 264 \\
(49 \cdot 2), 262(100), 260(76 \cdot 5), 251(5 \cdot 8), 249(27 \cdot 3), 247 \\
(55 \cdot 7), 245(43 \cdot 9)\end{array}$ \\
\hline 2,3,5,6-Tetrachloro-1,4-dimethoxybenzene & $11 \cdot 54$ & $\begin{array}{l}282(3 \cdot 1), 280(9 \cdot 4), 278(30 \cdot 4), 276(67 \cdot 3), 274(41 \cdot 9), \\
267(2 \cdot 7), 265(12 \cdot 3), 263(54 \cdot 2), 261(100), 259(82 \cdot 2), \\
213(16 \cdot 0), 211(48 \cdot 5), 209(51 \cdot 1)\end{array}$ \\
\hline 2,3,6-Trichloro-1,4-diacetoxybenzene & $12 \cdot 06$ & $\begin{array}{l}300(1 \cdot 1), 298(2 \cdot 8), 296(3 \cdot 2), 258(4 \cdot 2), 256(12 \cdot 2), 254 \\
(12 \cdot 5), 216(30 \cdot 9), 214(96 \cdot 3), 212(100)\end{array}$ \\
\hline 2,3,6-Trichloro-1-acetoxy-4-methoxybenzene & $10 \cdot 91$ & $\begin{array}{l}272(1 \cdot 9), 270(4 \cdot 1), 268(5 \cdot 5), 230(25 \cdot 1), 228(94 \cdot 5), 226 \\
(100), 215(22 \cdot 5), 213(70 \cdot 7), 211(72 \cdot 5), 177(11 \cdot 5), 175 \\
(18 \cdot 6)\end{array}$ \\
\hline 2,3,6-Trichloro-1,4-dimethoxybenzene & $10 \cdot 54$ & $\begin{array}{l}244(14 \cdot 4), 242(40 \cdot 0), 240(47 \cdot 3), 229(30 \cdot 8), 227(97 \cdot 9) \text {, } \\
225(100), 177(31 \cdot 1), 175(47 \cdot 3)\end{array}$ \\
\hline 2,6-Dichloro-1,4-di(TMS)benzene & $11 \cdot 08$ & $\begin{array}{l}326(9 \cdot 1), 324(64 \cdot 4), 322(90 \cdot 0), 311(5 \cdot 1), 309(33 \cdot 2), \\
307(48 \cdot 5), 274(33 \cdot 4), 272(100)\end{array}$ \\
\hline 2,5-Dichloro-1,4-di(TMS)benzene & $10 \cdot 58$ & $\begin{array}{l}326(11 \cdot 1), 324(65 \cdot 8), 322(100), 311(3 \cdot 9), 309(26 \cdot 1), \\
307(38 \cdot 5), 274(23 \cdot 2), 272(68 \cdot 7)\end{array}$ \\
\hline Dichlorotriacetoxybenzene & $14 \cdot 01$ & $\begin{array}{l}324(0 \cdot 2), 322(2 \cdot 1), 320(3 \cdot 7), 282(1 \cdot 1), 280(5 \cdot 1), 278 \\
(10 \cdot 1), 240(3 \cdot 4), 238(17 \cdot 3), 236(22 \cdot 8), 198(10 \cdot 2), 196 \\
(63 \cdot 8), 194(100)\end{array}$ \\
\hline
\end{tabular}

*TMS, trimethylsilyloxy.

chlorobenzoquinone (II). Tetrachlorodihydroxybenzene (III) was oxidized by both $\mathrm{LiP}$ and $\mathrm{MnP}$ to its corresponding benzoquinone. No products indicative of oxidative dechlorination of tetrachlorodihydroxybenzene by LiP or MnP were observed. The benzoquinone (II) was identified by comparing its retention time with that of the standard compound using HPLC. Furthermore, the reduced and acetylated derivative of the benzoquinone (II) was identified by GC-MS (Table 1).

\section{Reduction of tetrachlorobenzoquinone (II)}

Six-day-old cultures of $P$. chrysosporium, as well as 6-dold washed hyphae, resuspended in buffer, readily converted tetrachlorobenzoquinone (II) to tetrachlorodihydroxybenzene (III) with greater than $80 \%$ conversion within $1 \mathrm{~h}$ at $37^{\circ} \mathrm{C}$. In contrast, only minimal conversion of the quinone to the hydroquinone $(\sim 6 \%$ in $1 \mathrm{~h}$ ) occurred with the filtered extracellular medium from 6-d-old cultures, suggesting that the chloroquinone reduction activity is cell-associated.

\section{DISCUSSION}

White-rot basidiomycetous fungi are primarily responsible for the initial depolymerization of lignin in wood (Buswell \& Odier, 1987; Kirk \& Farrell, 1987; Gold et al., 1989; Higuchi, 1990). The best-studied white-rot fungus, $P$. chrysosporium, degrades lignin during secondary metabolic (idiophasic) growth (Kirk et al., 1978; Buswell \& Odier, 1987; Kirk \& Farrell, 1987; Gold et al., 1982, 1989; Higuchi, 1990). P. chrysosporium is also capable of mineralizing a variety of persistent environmental pollutants (Huynh et al., 1985; Bumpus \& Aust, 1987; Valli \& Gold, 1991; Joshi \& Gold, 1993; 


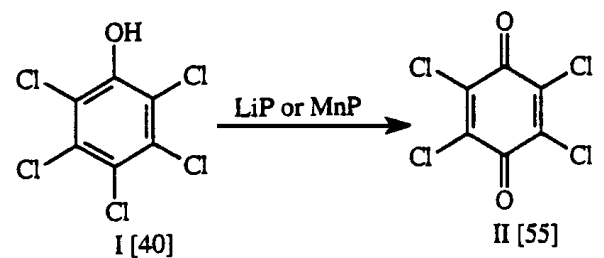

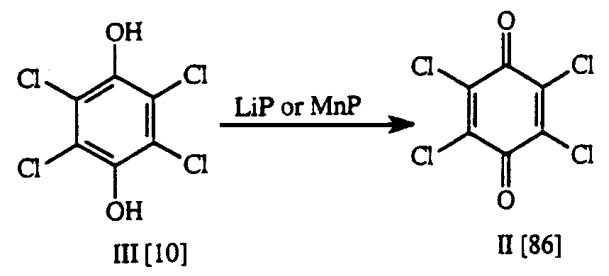

Fig. 3. Products identified from the oxidation of $P C P$ and tetrachlorodihydroxybenzene by purified LiP and MnP. Reaction conditions and identification of products were as described in Methods. Percentages of substrate remaining and product yields (\%) are given in square brackets and were determined by HPLC as described in Methods. Roman numerals identifying compounds in the figure correspond to those in the text.

Armenante et al., 1994), including PCP (Mileski et al., 1988). An initial degradation intermediate, tetrachlorobenzoquinone, has been identified (Hammel \& Tardone, 1988; Mileski et al., 1988). However, to date the complete degradation pathway for PCP has not been elucidated in any eukaryote. Here, we confirm that $P$. chrysosporium degrades PCP under nitrogen-limiting conditions (Mileski et al., 1988), suggesting that the lignin degradative system is responsible, at least in part, for the degradation of this compound. However, we also show that the key metabolite tetrachlorodihydroxybenzene is readily degraded under both nitrogensufficient and nitrogen-limiting conditions, suggesting that other enzymes are involved in the PCP degradation pathways and that extracellular peroxidases apparently are involved only in the initial step, the oxidation of PCP to tetrachlorobenzoquinone. The remaining steps in the pathway are carried out under both HC/LN and $\mathrm{HC} / \mathrm{HN}$ conditions, suggesting they may not be part of the classical lignin degradative system (Kirk \& Farrell, 1987).

The sequential identification of primary metabolites produced during PCP degradation by P. chrysosporium, and the subsequent identification of secondary metabolites following the addition of primary metabolites to fungal cultures, allows us to propose interlinking pathways for the degradation of this pollutant. The first step in the pathway(s) is the LiP- or $\mathrm{MnP}$-catalysed oxidation of PCP to tetrachlorobenzoquinone (II). Similar oxidative dechlorination reactions catalysed by $\mathrm{LiP}$ and $\mathrm{MnP}$ have been reported for several chlorinated phenols (Joshi \& Gold, 1993; Hammel \& Tardone, 1988; Mileski et al., 1988; Reddy et al., 1998).

Tetrachlorodihydroxybenzene (III) was identified as the major metabolite obtained from tetrachlorobenzo- quinone (II) in reactions carried out by intact cells, suggesting that quinone reduction is the next step in the pathway(s). A similar quinone reduction step was observed previously during the degradation of other polychlorinated phenols (Valli \& Gold, 1991; Joshi \& Gold, 1993; Reddy et al., 1998). Chloroquinones are strong oxidants which may be converted to their corresponding hydroquinones, either enzymically or nonenzymically. Tetrachlorobenzoquinone is converted to its corresponding hydroquinone (III) much more efficiently by washed cells than by filtered extracellular medium. In contrast, the first step in the bacterial degradation of PCP (I) is a parahydroxylation yielding tetrachlorodihydroxybenzene (III) directly (Häggblom et al., 1989; Xun \& Orser, 1991; Xun et al., 1992).

Metabolites produced from tetrachlorodihydroxybenzene (III) included tetrachlorobenzoquinone (II), trichlorodihydroxybenzene $(\mathrm{V})$ and dichlorotrihydroxybenzene (VII). The formation of trichlorodihydroxybenzene $(\mathrm{V})$ indicates that reductive dechlorination is occurring. We have recently reported that 2,6-dichloro1,4-dihydroxybenzene is reductively dechlorinated to 2-chlorohydroquinone by $P$. chrysosporium (Reddy et al., 1998). Reductive dechlorination of tetrachlorodihydroxybenzene (III) has been reported in bacterial systems (Steiert \& Crawford, 1986; Apajalahti \& Salkinoja-Salonen, 1987; Xun \& Orser, 1992). Our results also demonstrate that $\mathrm{MnP}$ and $\mathrm{LiP}$ oxidize tetrachlorodihydroxybenzene (III) to tetrachlorobenzoquinone (II) with no oxidative dechlorination products observed, suggesting that the oxidative dechlorination of tetrachlorodihydroxybenzene (III) is probably not a significant reaction in the further degradation of this metabolite. Trichlorotrihydroxybenzene (VI) was identified as a metabolite of tetrachlorodihydroxybenzene (III), and VI was also formed when tetrachlorobenzoquinone (II) was incubated in water. Thus, the formation of VI from III is probably due to the initial oxidation of III to the benzoquinone (II), which could undergo a nonenzymic 1,4-addition of $\mathrm{H}_{2} \mathrm{O}$ (Finley, 1974; Joshi \& Gold, 1994) (Fig. 4). Trichlorotrihydroxybenzene was also proposed as a metabolite of PCP degradation by the fungus Mycena avenacea (Kremer et al., 1992).

Trichlorodihydroxybenzene (V) was reductively dechlorinated to yield 2,5-dichlorodihydroxybenzene (XI). Mass fragmentation patterns of the trimethylsilyloxy derivatives of 2,5-dichlorodihydroxybenzene and 2,6-dichlorodihydroxybenzene can be distinguished (Table 1), enabling the observed metabolite to be unequivocally identified as 2,5-dichlorodihydroxybenzene (XI). In the present study, dichlorotrihydroxybenzene (VII) and 3,5,6-trichlorotrihydroxybenzene (VI) were also metabolites of trichlorodihydroxybenzene $(\mathrm{V})$, suggesting that $\mathrm{V}$ is either enzymically hydroxylated or undergoes oxidation followed by 1,4-addition to produce VI (Joshi \& Gold, 1994) and that the latter is reductively dechlorinated to generate VII. Reductive dechlorination of V, followed by hydroxylation of the product XI, would also yield 

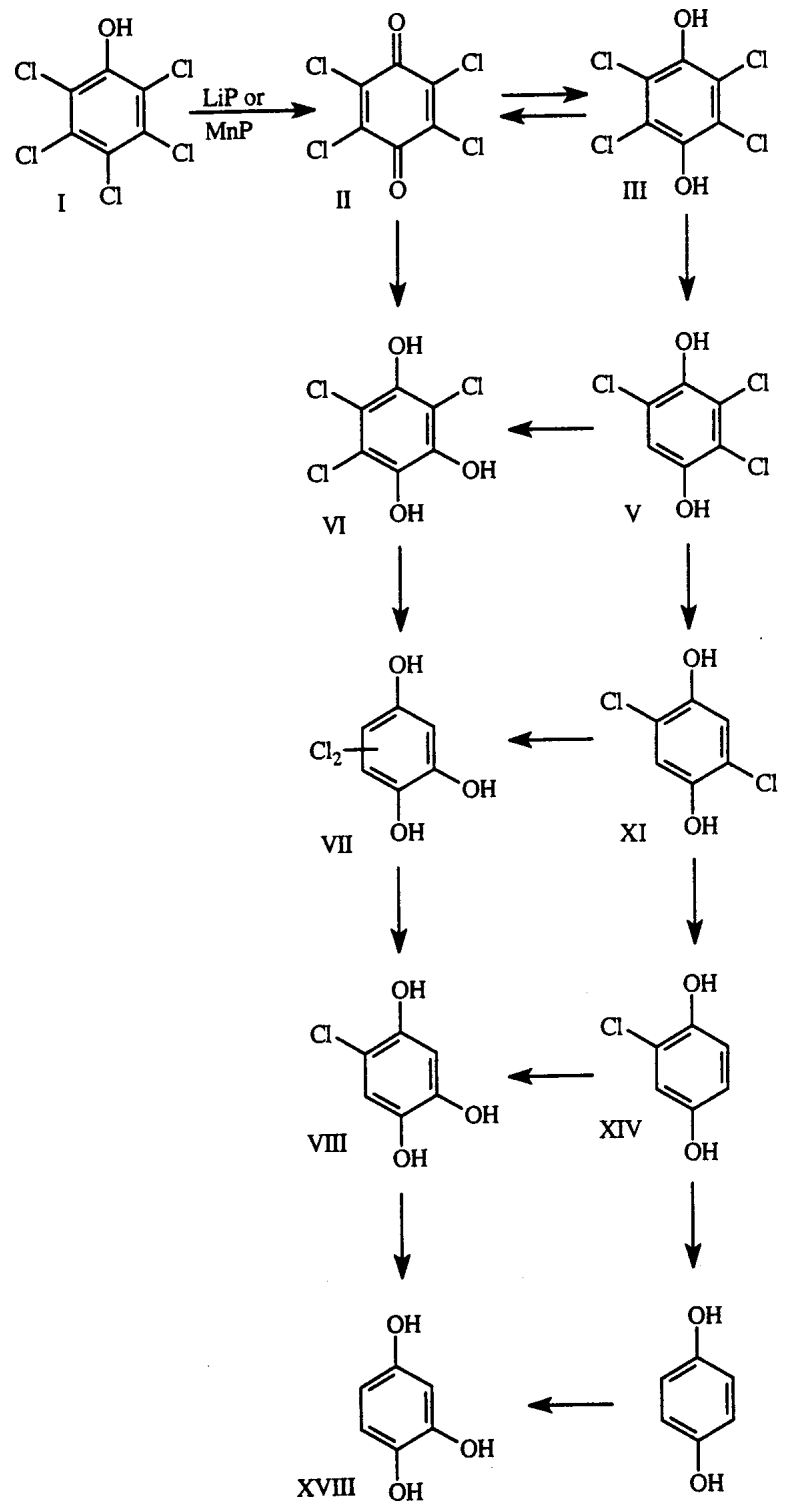

Fig. 4. Proposed pathway(s) for the degradation of PCP (I) by $P$. chrysosporium. Roman numerals identifying compounds in the figure correspond to those in the text.

VII. The hydroxylation of $p$-hydroquinone and chlorohydroquinone has been demonstrated previously (Reddy et al., 1998). Dichlorotrihydroxybenzene (VII) was reductively dechlorinated to produce 5-chloro-1,2,4trihydroxybenzene as the only product.

Finally, when 2,5-dichlorodihydroxybenzene (XI) was added to cultures, it was further reductively dechlorinated to 2-chloro-1,4-dihydroxybenzene (XIV). Other metabolites included chlorotrihydroxybenzene (VIII), dichlorotrihydroxybenzene (XVII) and trihydroxybenzene (XVIII). We have reported that 2,6dichlorodihydroxybenzene also is converted to chlorodihydroxybenzene (Reddy et al., 1998). We also showed that the further reductive dechlorination of chlorodihydroxybenzene (XIV) either precedes or follows hydroxylation of chlorodihydroxybenzene (XIV) to produce the key aromatic metabolite trihydroxybenzene (Reddy et al., 1998). The conversion of 2,5-dichloro1,4-dihydroxybenzene (XI) to chlorotrihydroxybenzene (VIII) probably occurs via an initial reductive dechlorination to generate XIV, followed by hydroxylation to generate VIII (Fig. 4). Apparently, hydroxylation is also an important reaction in the dechlorination of polychlorophenols.

The methylation of phenols and hydroquinones by $P$. chrysosporium cultures has been observed previously during the degradation of various aromatic compounds (Lamar et al., 1990; Valli \& Gold, 1991; Joshi \& Gold, 1993; Armenante et al., 1994; Reddy et al., 1998). Our results show that PCP (I) was methylated by $P$. chrysosporium under HC/HN conditions. However, metabolically stable methylated compounds do not accumulate in $\mathrm{HC} / \mathrm{LN}$ cultures when PCP is rapidly degraded. Thus, the methylation reaction is probably not a major metabolic step in the degradation of PCP under HC/LN conditions. Under $\mathrm{HC} / \mathrm{HN}$ conditions, PCP was slowly methylated to form pentachloroanisole as the sole product $(\sim 1 \%$ product formed after $3 \mathrm{~d})$. The transformation of PCP metabolites, including tetrachlorodihydroxybenzene but not PCP, occurs under $\mathrm{HC} / \mathrm{HN}$ conditions in a manner similar to that observed under $\mathrm{HC} / \mathrm{LN}$ conditions (Fig. 2). This suggests that the initial oxidative dechlorination occurs only under HC/LN ligninolytic conditions, but that subsequent steps, including reductive dechlorination and hydroxylation, can occur under either primary or secondary metabolic growth conditions.

Based on our present and previous results, we propose a pathway(s) for the complete dechlorination of PCP (Fig. 4). PCP (I) is first oxidized by LiP or MnP to tetrachlorobenzoquinone (II), which apparently is further degraded by two parallel pathways with several crosspathway steps. In the first pathway, tetrachlorobenzoquinone (II) is reduced to tetrachlorodihydroxybenzene (III) by an enzymic or nonenzymic process. The latter undergoes four successive reductive dechlorinations through trichlorodihydroxybenzene $(\mathrm{V})$, dichlorodihydroxybenzene (XI), monochlorodihydroxybenzene (XIV) and finally to 1,4-dihydroxybenzene which is $o$-hydroxylated to form trihydroxybenzene (XVIII). The hydroxylation of 1,4-dihydroxybenzene was demonstrated in our earlier work (Reddy et al., 1998). Alternatively, tetrachlorobenzoquinone (II) is converted to trichlorotrihydroxybenzene (VI) by a 1,4addition reaction (Joshi \& Gold, 1994). The latter can undergo three successive reductive dechlorinations to form trihydroxybenzene (XVIII). In addition, at the trichloro-, dichloro- and monochlorodihydroxybenzene levels, an hydroxylation reaction can redirect the metabolic flow from one pathway to the other (Fig. 4). We showed earlier that trihydroxybenzene is ring-cleaved to form maleyl acetate by a trihydroxybenzene dioxygenase (Rieble et al., 1994). Finally, in previous work (Reddy et al., 1998) we used filtration and plating assays as well as PCR methods to demonstrate that this 
pathway is carried out by the fungus rather than by bacterial contaminants.

PCP degradation has been studied extensively in the prokaryote $S$. chlorophenolica; a PCP monooxygenase and a tetrachlorodihydroxybenzene reductive dehalogenase have been purified from this organism (Xun \& Orser, 1991, 1992). However, to our knowledge, this is the first report of a pathway(s) for the complete dechlorination of PCP by a eukaryote. Recently, we published a study on a two-component enzymic system which reductively dechlorinates tetrachlorohydroquinone (III) to produce trichlorohydroquinone (V) in cell-free extracts of $P$. chrysosporium (Reddy \& Gold, 1999). This cell-free system also reductively dechlorinates trichlorohydroquinone $(\mathrm{V})$ and dichlorohydroquinone (XI). We are now attempting to purify the two enzyme components of this novel reductive dechlorination system. Finally, this work as well as our previous studies (Reddy et al., 1998; Reddy \& Gold, 1999) clearly show that this fungus is able to degrade PCP via a combination of extracellular oxidative and intracellular reductive dechlorination reactions.

\section{ACKNOWLEDGEMENTS}

This research was supported by grant DE-FG03-96ER20235 from the US Department of Energy, Division of Energy Biosciences, and grant 2-4722-03 from the US Department of Agriculture.

\section{REFERENCES}

Alic, M., Letzring, C. \& Gold, M. H. (1987). Mating system and basidiospore formation in the lignin-degrading basidiomycete Phanerochaete chrysosporium. Appl Environ Microbiol 53, 1464-1469.

Apajalahti, J. H. A. \& Salkinoja-Salonen, M. S. (1987). Complete dechlorination of tetrachlorohydroquinone by cell extracts of pentachlorophenol-induced Rhodococcus chlorophenolicus. J Bacteriol 169, 5125-5130.

Armenante, P. M., Pal, N. \& Lewandowski, G. (1994). Role of mycelium and extracellular protein in the biodegradation of 2,4,6-trichlorophenol by Phanerochaete chrysosporium. Appl Environ Microbiol 60, 1711-1718.

Bumpus, J. A. \& Aust, S. D. (1987). Biodegradation of environmental pollutants by the white rot fungus Phanerochaete chrysosporium: involvement of the lignin-degrading system. Bioessays 6, 166-170.

Buswell, J. A. \& Odier, E. (1987). Lignin degradation. Crit Rev Biotechnol 6, 1-60.

Chu, J. P. \& Kirsch, E. J. (1972). Metabolism of pentachlorophenol by an axenic bacterial culture. Appl Microbiol 23, 1033-1035.

Copley, S. D. (1998). Microbial dehalogenases: enzymes recruited to convert xenobiotic substrates. Curr Opin Chem 2, 613-617.

Crosby, D. G. (1981). Environmental chemistry of pentachlorophenol. Pure Appl Chem 63, 1051-1080.

Finley, K. T. (1974). The addition and substitution chemistry of quinones. In The Chemistry of the Quinonoid Compounds, Part 2, pp. 877-1144. Edited by S. Patai. London: Wiley.

Friedman, D. \& Ginsburg, D. (1958). Halogenation of pyrogallol trimethyl ether and similar systems. J Org Chem 23, 16-17.
Furniss, B. S., Hannaford, A. J., Smith, P. W. G. \& Tatchell, A. R. (revisors) (1989). Solvents and reagents. In Vogel's Textbook of Practical Organic Chemistry, 5th edn, pp. 395-469. Essex, UK: Longman Scientific \& Technical.

Glenn, J. K. \& Gold, M. H. (1985). Purification and characterization of an extracellular $\mathrm{Mn}(\mathrm{II})$-dependent peroxidase from the lignindegrading basidiomycete, Phanerochaete chrysosporium. Arch Biochem Biophys 242, 329-341.

Gold, M. H., Mayfield, M. B., Cheng, T. M., Krisnangkura, K., Enoki, A., Shimada, M. \& Glenn, J. K. (1982). A Phanerochaete chrysosporium mutant defective in lignin degradation as well as several other secondary metabolic functions. Arch Microbiol 132, 115-122.

Gold, M. H., Kuwahara, M., Chiu, A. A. \& Glenn, J. K. (1984). Purification and characterization of an extracellular $\mathrm{H}_{2} \mathrm{O}_{2}$ requiring diarylpropane oxygenase from the white rot basidiomycete Phanerochaete chrysosporium. Arch Biochem Biophys 234, 353-362.

Gold, M. H., Wariishi, H. \& Valli, K. (1989). Extracellular peroxidases involved in lignin degradation by the white rot basidiomycete Phanerochaete chrysosporium. ACS Symp Ser 389, 127-140.

Häggblom, M. M., Janke, D. \& Salkinoja-Salonen, M. S. (1989). Hydroxylation and dechlorination of tetrachlorohydroquinone by Rhodococcus sp. strain CP-2 cell extracts. Appl Environ Microbiol 55, 516-519.

Häggblom, M. M., Nohynek, L. J., Palleroni, N. J., Kronqvist, K., Nurmiaho-Lassila, E.-L., Salkinoja-Salonen, M. S., Klatte, S. \& Kroppenstedt, R. M. (1994). Transfer of polychlorophenol-degrading Rhodococcus chlorophenolicus (Apajalahti et al. 1986) to the genus Mycobacterium as Mycobacterium chlorophenolicum comb. nov. Int J Syst Bacteriol 44, 485-493.

Hammel, K. E. \& Tardone, P. J. (1988). The oxidative 4dechlorination of polychlorinated phenols is catalyzed by extracellular fungal lignin peroxidases. Biochemistry 27, 6563-6568.

Higuchi, T. (1990). Lignin biochemistry: biosynthesis and biodegradation. Wood Sci Technol 24, 23-63.

Huynh, V. B., Chang, H. M., Joyce, T. W. \& Kirk, T. K. (1985). Dechlorination of chloro-organics by a white-rot fungus. Tech Assoc Pulp Pap Indian J 68, 98-102.

Joshi, D. K. \& Gold, M. H. (1993). Degradation of 2,4,5trichlorophenol by the lignin-degrading basidiomycete Phanerochaete chrysosporium. Appl Environ Microbiol 59, 1779-1785.

Joshi, D. K. \& Gold, M. H. (1994). Oxidation of dibenzo-p-dioxin by lignin peroxidase from the basidiomycete Phanerochaete chrysosporium. Biochemistry 33, 10969-10976.

Keither, L. H. \& Teilard, W. A. (1979). Priority pollutants. I. A perspective view. Environ Sci Technol 13, 416-423.

Kirk, T. K. \& Farrell, R. L. (1987). Enzymatic “combustion": the microbial degradation of lignin. Annu Rev Microbiol 41, 465-505.

Kirk, T. K., Schultz, E., Connors, W. J., Lorenz, L. F. \& Zeikus, J. G. (1978). Influence of culture parameters on lignin metabolism by Phanerochaete chrysosporium. Arch Microbiol 117, 277-285.

Kremer, S., Sterner, O. \& Heidrun, A. (1992). Degradation of pentachlorophenol by Mycena avenacea TA 8480 - identification of initial dechlorinated metabolites. Z Naturforsch 47C, 561-566.

Lamar, R. T., Larsen, M. J. \& Kirk, T. K. (1990). Sensitivity to and degradation of pentachlorophenol by Phanerochaete spp. Appl Environ Microbiol 56, 3519-3526.

Mileski, G. J., Bumpus, J. A., Jurek, M. A. \& Aust, S. D. (1988). Biodegradation of pentachlorophenol by the white rot fungus 
Phanerochaete chrysosporium. Appl Environ Microbiol 54, 2885-2889.

Moos, L. P., Kirsch, E. J., Wukasch, R. F. \& Grady, C. P. L. (1983). Pentachlorophenol biodegradation. Water Res 17, 1575-1584.

Radehaus, P. M. \& Schmidt, S. K. (1992). Characterization of a novel Pseudomonas sp. that mineralizes high concentrations of pentachlorophenol. Appl Environ Microbiol 58, 2879-2885.

Reddy, G. V. B. \& Gold, M. H. (1999). A two-component tetrachlorohydroquinone reductive dehalogenase system from the lignin-degrading basidiomycete Phanerochaete chrysosporium. Biochem Biophys Res Commun 257, 901-905.

Reddy, G. V. B., Sollewijn Gelpke, M. D. \& Gold, M. H. (1998). Degradation of 2,4,6-trichlorophenol by Phanerochaete chrysosporium: involvement of reductive dechlorination. J Bacteriol 180, 5159-5164.

Rieble, S., Joshi, D. K. \& Gold, M. H. (1994). Purification and characterization of a 1,2,4-trihydroxybenzene 1,2-dioxygenase from the basidiomycete Phanerochaete chrysosporium. J Bacteriol 176, 4838-4844.

Saber, D. L. \& Crawford, R. L. (1985). Isolation and characterization of Flavobacterium strains that degrade pentachlorophenol. Appl Environ Microbiol 50, 1512-1518.

Schenk, T., Muller, R., Morsberger, F., Otto, M. K. \& Lingens, F. (1989). Enzymatic dehalogenation of pentachlorophenol by extracts from Arthrobacter sp. strain ATCC 33790. J Bacteriol $171,5487-5491$.

Steiert, J. G. \& Crawford, R. L. (1986). Catabolism of pentachlorophenol by a Flavobacterium sp. Biochem Biophys Res Commun 141, 825-830.

Valli, K. \& Gold, M. H. (1991). Degradation of 2,4-dichlorophenol by the lignin-degrading fungus Phanerochaete chrysosporium. J Bacteriol 173, 345-352.

Wariishi, H. \& Gold, M. H. (1990). Lignin peroxidase compound III. Mechanism of formation and decomposition. J Biol Chem 265, 2070-2077.

Xun, L. \& Orser, C. S. (1991). Purification and properties of pentachlorophenol hydroxylase, a flavoprotein from Flavobacterium sp. strain ATCC 39723. J Bacteriol 173, 4447-4453.

Xun, L. \& Orser, C. S. (1992). Purification and characterization of a tetrachloro- $p$-hydroquinone reductive dehalogenase from Flavobacterium sp. J Bacteriol 174, 8003-8007.

Xun, L., Topp, E. \& Orser, C. S. (1992). Diverse substrate range of a Flavobacterium pentachlorophenol hydroxylase and reaction stoichiometries. J Bacteriol 174, 2898-2902.

Received 13 July 1999; revised 19 October 1999; accepted 20 October 1999. 